\title{
Application of HR-ICP-MS techniques to constrain modern lead pollution sources in Greenland ice
}

\author{
Sophia M. Wensman ${ }^{1 *}$, Alyssa E. ShIEL ${ }^{1}$, JosePh R. \\ MCCONNELL ${ }^{2}$ \\ ${ }^{1}$ College of Earth, Ocean, and Atmospheric Sciences, Oregon \\ State University, Corvallis, OR, USA (*correspondence: \\ wensmans@oregonstate.edu) \\ ${ }^{2}$ Desert Research Institute, Reno, NV, USA
}

Glacial ice provides an opportunity to understand changes in global atmospheric lead $(\mathrm{Pb})$ pollution through examination of some of Earth's least disturbed areas. While analytical fingerprinting capabilities have improved, the number of $\mathrm{Pb}$ isotope measurements in ice cores remains limited. Small sample size and low $\mathrm{Pb}$ concentrations found in glacial ice (often only a few $\mathrm{pg} / \mathrm{g}$ ) have challenged analytical capabilities. Studies that measure $\mathrm{Pb}$ isotopes are limited either by lower precision (>0.2\% RSD) or opt for low temporal resolution in exchange for improved precision.

Recent advancements in low-level measurements of $\mathrm{Pb}$ by Attom high resolution inductively coupled plasma mass spectrometry (HR-ICP-MS) have been demonstrated in honey by Smith et al. (2019) ${ }^{[1]}$. Application of HR-ICP-MS techniques provides an opportunity to improve precision over previously used TIMS and ICP-MS. Preliminary results from the analysis of a Greenland core (1759-2009), indicate average analytical precision of $\sim 0.1 \%$ RSD for ${ }^{206} \mathrm{~Pb} /{ }^{207} \mathrm{~Pb}$ and ${ }^{208} \mathrm{~Pb} /{ }^{207} \mathrm{~Pb}$, constituting a $\geq 2$-fold increase in precision over previous methods. While ${ }^{204} \mathrm{~Pb}$ has been measured in glacial ice previously ${ }^{[2]-[5]}$, this study, to our knowledge represents the first time ${ }^{204} \mathrm{~Pb}$ will be used for its discrimination power to constrain pollution sources.

Initial interpretations suggest a predominant coal-derived signal in glacial ice from 1860 until $\sim 1930$ when leaded gasoline became a dominant source. Isotopic shifts suggest expansion of leaded gasoline use in North America until the early 1970s, after which isotopic signatures indicate predominantly Eurasian sources.

In addition to new insights into historical $\mathrm{Pb}$ emissions, this study indicates the possibility for expansion of these methods to other ice cores and media where low $\mathrm{Pb}$ levels make precise isotopic measurements analytically prohibitive.

${ }^{[1]}$ Smith, K.E., et al. (2019), Nat. Sustainability, 2(3), 223232. ${ }^{[2]}$ Rosman, K.J.R., et al. (1994), Geochim. Cosmochim. Acta, 58(15), 3265-3269. ${ }^{[3]}$ Rosman, K.J.R., et al. (1997), Environ. Sci. Technol., 31(12), 3413-3416. ${ }^{[4]}$ Rosman, K.J.R., et al. (2000), Earth Planet. Sci. Lett., 176(3-4), 413-424. ${ }^{[5]}$ Lee, K., et al. (2011), Sci. Total Environ., 412, 194-202. 